\title{
Development of Teaching Materials for Elementary Linear Algebra Through the Blended Learning Method
}

\author{
Yanita $^{1 *}$ and Nova Noliza Bakar ${ }^{2}$
}

\author{
1,2Department of Mathematic, Faculty of Mathematics and Natural Science, Universitas Andalas, Kampus Unand \\ Limau Manis, Padang 25163 - Indonesia \\ *Corresponding author. Email: yanita@sci.unand.ac.id
}

\begin{abstract}
This paper discusses the learning process of Elementary Linear algebra using blended learning which is carried out after the midterm exam. Learning is designed initially by providing additional explanation in the form of additional information that is used in such a way for a material. Furthermore, the development of teaching materials in the form of providing learning videos is provided in addition to the teaching materials and explanations. The purpose of this design is to improve students' understanding in learning Elementary Linear Algebra using the blended learning method.
\end{abstract}

Keywords: Blended learning, elementary linear algebra

\section{INTRODUCTION}

One of the learning outcomes expected from a Mathematics graduates is that students are expected to understand well the concepts and properties of mathematics related to Elementary Linear Algebra, students are also expected to have a critical attitude and always have the curiosity to question the reasons behind the emergence of definitions and theorems in mathematics. To realize this achievement, the Mathematics Department put it into a course entitled Elementary Linear Algebra.

Elementary Linear Algebra, Code PAM 132 is one of the compulsory subjects in the Department of Mathematics, Universitas Andalas. This course weighs 4 credits with a duration of 2 meetings in one week, with one meeting lasting 2 credits $(2 \times 50$ minutes $)$. In addition, this course has 1 meeting for tutorials of 2 credits and tutorials are also taught by Elementary Linear Algebra lecturers.
The material in this course includes systems of linear and matrix equations, determinants, vectors in 2 and 3 dimensional spaces, real vector spaces, inner product, characteristic values and characteristic vectors, and linear transformations. In tutorial meetings, it is usually done by giving and discussing questions, as well as discussing material which is considered to still need further explanation.

Assessment in this Elementary Linear Algebra course includes Mid- Semester Examination, Final Semester Examination, Analytical thinking skills (through quizzes and exercises), critical and logical thinking skills (through discussion and group assignments).

This lecture before Mid-Semester Examination was conducted conventionally, meaning face-to-face lectures in the classroom and accompanied by discussions or questions and answers. 
During this lecture process, there were not many obstacles, because every difficulty and obscurity in a material, can be asked directly.

As a basis for conducting this research, the midterm score was used as an initial reference to see the extent to which the increase in student understanding in taking Elementary
Linear Algebra courses, which is carried out by direct methods (face to face) and online.

Lectures are considered not too disappointing by looking at the results of the midterm scores which are converted as letters, in the table and diagram as follows:

Tabel 1. Midterm Scores of Elementary Linear Algebra Academic Year 2019/2020 (even semester)

\begin{tabular}{cccc}
\hline Scores & Number of Student & Percentage & Grade \\
\hline $0-44$ & 5 & 11,36 & E \\
$45-49$ & 1 & 2,27 & $\mathrm{D}$ \\
$50-54$ & 3 & 6,82 & $\mathrm{C}$ \\
$55-59$ & 5 & 11,36 & $\mathrm{C}+$ \\
$60-64$ & 4 & 9,09 & $\mathrm{~B}-$ \\
$65-69$ & 7 & 15,91 & $\mathrm{~B}$ \\
$70-74$ & 5 & 11,36 & $\mathrm{~B}+$ \\
$75-79$ & 3 & 6,82 & $\mathrm{~A}-$ \\
$80-100$ & 11 & 25,00 & $\mathrm{~A}$ \\
\hline Total & 44 & 100 & \\
\hline
\end{tabular}

\section{Midterm Score of Elementary Linear Algebra 2019/2020}

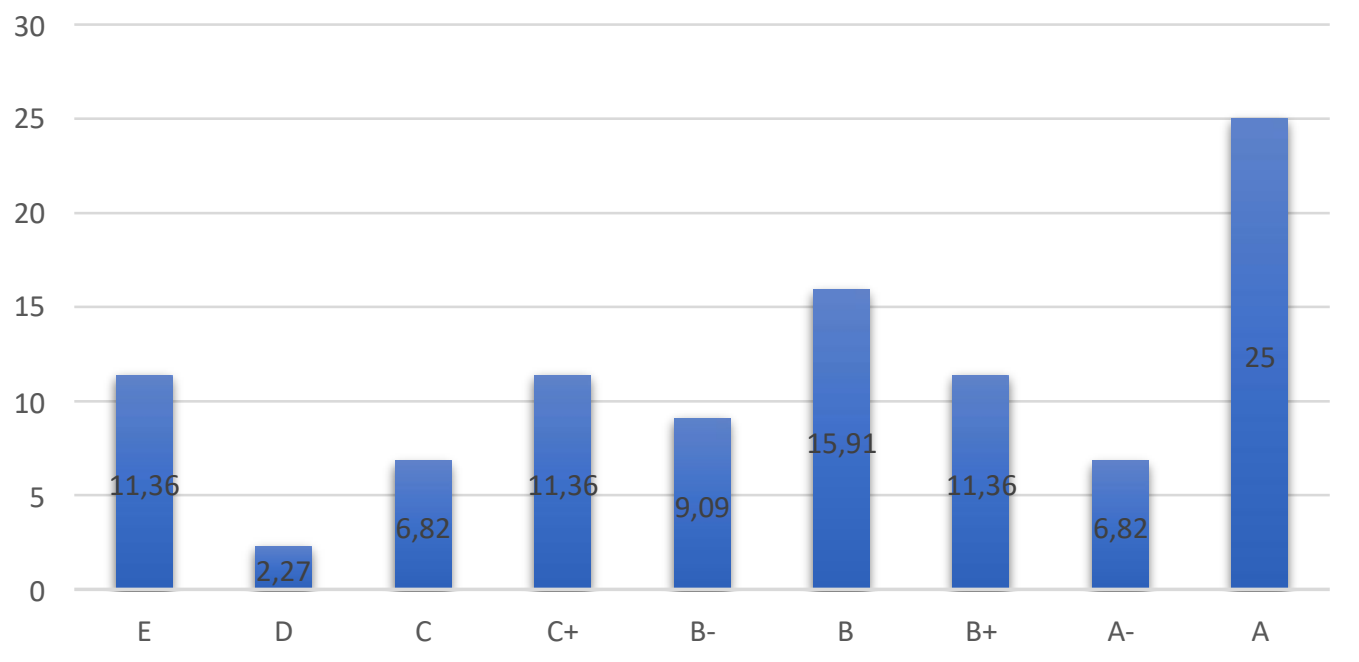

Figure 1. Distribution Midterm Score of Elementary Linear Algebra Academic Year 2019/2020 
In Figure 1, it can be seen that a good pass score starting from B is $59,09 \%$, meaning that more than $50 \%$ of students can understand this course material well. Furthermore, if you look at student graduation starting with a $\mathrm{C}$ grade, there are $86,36 \%$. So only $13,64 \%$ which is very disappointing.

When viewed at a glance from the point of view of the Teaching and Learning Process, this course has gone well with reference to the Semester Learning Plan. For example, this can be seen from the development of teaching materials through the making of lecture handouts for each meeting, the availability of text books in the library as well as those that can be accessed freely on the internet and the teaching lecturers have also made textbooks for Elementary Linear Algebra with guidance from main reference book. However, the student's ability to understand the theory contained in the textbook cannot be done by students without being preceded by information from the lecturer.

Problems then arose due to the Covid 19 outbreak throughout the world and also impacted lecture activities. Simultaneously, face-to-face lectures ended all over Indonesia, including Universitas Andalas. Finally after midterm, 100\% of lectures are conducted online and Elementary Linear Algebra is one of the courses that carry out this online course.

\section{Kesulitan dalam memahami perkuliahan daring (jawaban boleh lebih dari satu) 26 responses}

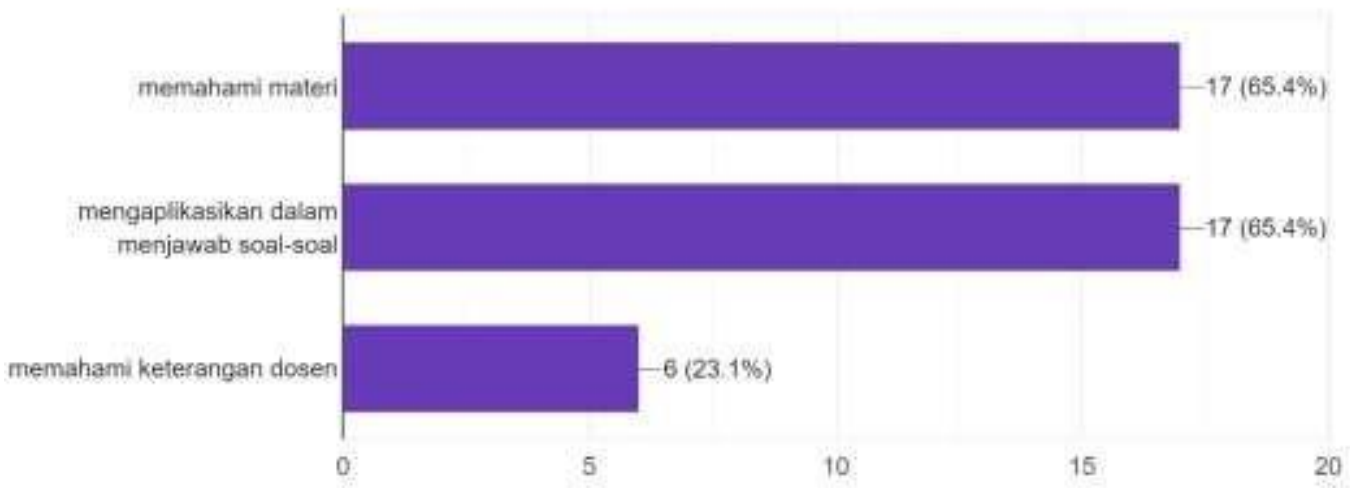

Researchers carry out online lectures using the I-learning assistance of Andalas University, especially in uploading lecture materials and tutorial materials. In addition, they also use the Zoom application and WhatsApp Group. Researchers also conducted an initial questionnaire to determine the extent to which students could receive these online lectures.
From the results of the respondent, it was found that $65.4 \%$ of students had difficulty understanding the material, $65.4 \%$ of students had difficulty applying it in answering questions, and $23.1 \%$ of students had difficulty understanding lecturers' information.

Furthermore, with the existing lectures, the researcher also asked whether additional explanations in the form of videos or the like were 
needed. It turns out that $93.3 \%$ of respondents said yes. So far, lecture explanations have been mostly done in writing and uploaded to learning and WhatsApp Group.
Researchers try their best to pour lecture material in language that is easy to understand and provide only 4 video lectures. On that basis, the researcher also asked the following:

\section{Apakah diperlukan penjelasan tambahan? (video atau sejenisnya\&gt: 30 responses}

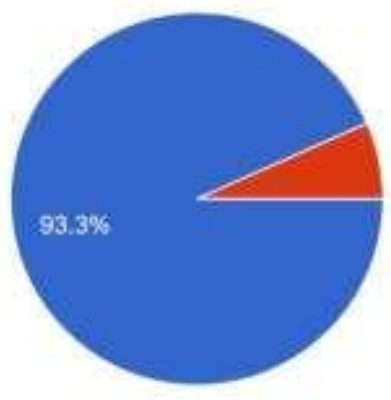

Based on this answer, the researcher adds to the video of the lecture and later will be tested whether the provision of video lectures can improve students' ability to understand Elementary Linear Algebra course material through online lectures.

\section{LITERATURE REVIEW}

Blended learning is the thoughtful fusion of face-to-face and online learning experiences. The basic principle is that face-to-face oral communication and online written communication are optimally integrated such that the strengths of each are blended into a unique learning experience congruent with the context and intended educational purpose. Although the concept of blended learning may be intuitively apparent and simple, the practical application is more complex. Blended learning is not an addition that simply builds another expensive educational layer. It represents a restructuring of class contact hours with the goal to enhance engagement and to extend access to Internet-based learning opportunities. Most important, blended learning is a fundamental redesign that transforms the structure of, and approach to, teaching and learning.

The key assumptions of a blended learning design are

- Thoughtfully integrating face-to- face and online learning

- Fundamentally rethinking the course de-sign to optimizestudent engagement

- Restructuring and replacing traditional class contact hours

Blended learning must be approached with the awareness of the broad range of flexible design possibilities and the challenge of doing things differently. It must be based upon a sound understanding of higher-order learning environments, communication characteristics, requirements of various disciplines, and resources. Blended learning redesign is a catalyst; it means to fundamentally reconceptualize and restructure the teaching and learning transaction. Its basic assumption 
is to open the educational mind to a full range of possibilities. Blended learning brings into consideration a range in deep and meaningful ways. Blended learning is no more about reshaping and enhancing the traditional classroom than it is about making e-learning more acceptable. In both contexts one is left with essentially either face-to-face or online learning.

According to Thorne [8] blended learning is the most logical and natural evolution of the learning agenda. This requires an elegant solution to the challenge of tailoring learning and development to individual needs. It is also an opportunity to integrate the innovative advances and technology offered by online learning with the best interaction and participation offered in traditional learning. This can be supported and enhanced by using the personal trainer's discretion and personal contact.

Blended learning is a mixture of:

- multimedia technology;

- Streaming video CD ROMs;

- virtual classrooms;

- voicemail, e-mail and conference calls;

- online text animation and video streaming.

Blended learning is a way to complement faceto-face classes with web- based materials [1]. This learning style is usually defined as the integration of traditional classroom methods with online activities (called "e-learning") [1, 3, 5]. But this blended learning method was developed to complement, not replace, traditional forms of learning [6].

According to [2], the main aspects of teaching and learning are students' own experiences of the process. However, works published on blended learning focus more on different teaching methods and on innovations that are introduced rather than on student experiences $[4,7]$ of options that require revisiting how students learn.
Linear algebra is one of the compulsory subjects in Department of Mathematics, Andalas University. This course has a weight of 4 credits with meetings 2 times a week. This course is also equipped with a tutorial meeting by supporting lecturers. Based on the material in this course, then this subject, according to most students, is one of the subjects in the difficult category. This can be seen from the final grades of students and the number of students who take this course again.

Most of the material in Linear Algebra is theories (ie, theorems, lemmas, propositions and corollaries) which must be proven by various methods of proof in mathematics. Difficulties of students are usually in using the method of proof (steps that must be taken so that the proof is correct). This basically makes it difficult for students to learn the theory themselves. Based on this, lecturers must be careful if they want to give lectures with indirect methods, such as blended learning.

\subsection{Material for Elementary Linear Algebra in Blended Learning}

This research was conducted within one semester. Because the researcher wants to see the effect of blended learning in improving student understanding in Linear Algebra, there are two phases of assessment. In the first phase, researchers conducted classroom observations without including blended learning, which is the initial lecture period until midterm; the next phase is the end of the midterm to the end of the semester. In this phase the researcher includes blended learning. Following is a rubric table of student responses in the first phase 
Table 2. Student Understanding Level Rubric (Without Blended Learning)

\begin{tabular}{lll}
\hline Grade & Score & Indicator \\
\hline Less & $0-5$ & $\begin{array}{l}\text { Students do not understand the theory (do not know the } \\
\text { premise and the part that must be concluded) } \\
\text { Sufficient }\end{array}$ \\
Good & $6-10$ & $\begin{array}{l}\text { Students understand the theory, but cannot write proof } \\
\text { steps, resulting in wrong conclusions } \\
\text { Students understand the theory and students are able to } \\
\text { write the steps, but there is a little wrong placement of } \\
\text { additional theories to reach conclusions } \\
\text { Students understand the theory and students are able to } \\
\text { write proof steps correctly until a conclusion is reached }\end{array}$ \\
Very Good & $11-15-20$ &
\end{tabular}

Table 3. Student Understanding Level Rubric (With Blended Learning)

\begin{tabular}{lll}
\hline Grade & Skor & Indikator \\
\hline Less & $0-6$ & $\begin{array}{l}\text { Students do not understand the theory (do not know the } \\
\text { premise and the part that must be concluded) }\end{array}$ \\
Sufficient & $7-13$ & $\begin{array}{l}\text { Students understand the theory, but cannot write proof } \\
\text { steps, resulting in wrong conclusions } \\
\text { Gtudents understand the theory and students are able to } \\
\text { write the steps, but there is a little wrong placement of } \\
\text { additional theories to reach conclusions } \\
\text { Students understand the theory and students are able to } \\
\text { write proof steps correctly until a conclusion is reached }\end{array}$ \\
\hline
\end{tabular}

The difference in scores on the rubric given for the reasons in Table 1 of pure lectures uses a face-to-face system, whereas in Table 2, there is a combination of face-to-face lectures and blended learning, and there is even material that is given entirely with blended learning.

The design provided in blended learning as is done in general, namely providing lecture material through the media. At this stage the media used is whatsapp group. Researchers form discussion groups by first providing lecture material. The material provided in the form of narration, as well as explaining in class (due to the limitations of researchers, lecture material use video).

The following are examples of giving material by researchers:

Lecture Note 4.2. Ortoghonal Bases Definition 4.2.1
Let $\langle$,$\rangle be a inner product in vector space V$. Bases $\left\{\boldsymbol{u}_{1}, \boldsymbol{u}_{2}, \ldots, \boldsymbol{u}_{n}\right\}$ is orthogonal for $V$ if $\left\langle\boldsymbol{u}_{i}, \boldsymbol{u}_{j}\right\rangle=0$ for $i \neq j$.

If each $\left\|\boldsymbol{u}_{i}\right\|=1$ (or each $\boldsymbol{u}_{i}$ is unit vector) then bases $\left\{\boldsymbol{u}_{1}, \boldsymbol{u}_{2}, \ldots, \boldsymbol{u}_{n}\right\}$ orthonormal.

Remark:

- Definition 4.2.1 states that the orthogonal bases is a base which has a different pair of elements is orthogonal. So suppose that

$\left\{\boldsymbol{u}_{1}, \boldsymbol{u}_{2}, \ldots, \boldsymbol{u}_{n}\right\}$ is orthogonal bases in a vector space with inner products, then

- $\left\langle\boldsymbol{u}_{1}, \boldsymbol{u}_{2}\right\rangle=0,\left\langle\boldsymbol{u}_{1}, \boldsymbol{u}_{3}\right\rangle=0$, $\left\langle\boldsymbol{u}_{1}, \boldsymbol{u}_{4}\right\rangle=0, \ldots,\left\langle\boldsymbol{u}_{1}, \boldsymbol{u}_{n}\right\rangle=0$,

- $\left\langle\boldsymbol{u}_{2}, \boldsymbol{u}_{3}\right\rangle=0,\left\langle\boldsymbol{u}_{2}, \boldsymbol{u}_{4}\right\rangle=$ $0, \ldots,\left\langle\boldsymbol{u}_{2}, \boldsymbol{u}_{n}\right\rangle=0$

- $\left\langle\boldsymbol{u}_{3}, \boldsymbol{u}_{4}\right\rangle=0, \ldots,\left\langle\boldsymbol{u}_{3}, \boldsymbol{u}_{n}\right\rangle=0$. $\vdots$

- $\left\langle\boldsymbol{u}_{n-1}, \boldsymbol{u}_{n}\right\rangle=0$

- Definition 4.2.1 states that orthonormal bases is orthogonal bases dan for every $\boldsymbol{u}_{n}$, then 
$\left\|\boldsymbol{u}_{i}\right\|=1, \quad=1,2, \ldots, n$. So let $\left\{\boldsymbol{u}_{1}, \boldsymbol{u}_{2}, \ldots, \boldsymbol{u}_{n}\right\}$ is orthonormal bases, then

- $\left\langle\boldsymbol{u}_{1}, \boldsymbol{u}_{2}\right\rangle=0,\left\langle\boldsymbol{u}_{1}, \boldsymbol{u}_{3}\right\rangle=0$, $\left\langle\boldsymbol{u}_{1}, \boldsymbol{u}_{4}\right\rangle=0, \ldots,\left\langle\boldsymbol{u}_{1}, \boldsymbol{u}_{n}\right\rangle=0$

- $\left\langle\boldsymbol{u}_{2}, \boldsymbol{u}_{3}\right\rangle=0,\left\langle\boldsymbol{u}_{2}, \boldsymbol{u}_{4}\right\rangle=0, \ldots,\left\langle\boldsymbol{u}_{2}, \boldsymbol{u}_{n}\right\rangle=0$

- $\left\langle\boldsymbol{u}_{3}, \boldsymbol{u}_{4}\right\rangle=0, \ldots\left\langle\boldsymbol{u}_{3}, \boldsymbol{u}_{n}\right\rangle=0$

$-\quad \vdots$

- $\left\langle\boldsymbol{u}_{n-1}, \boldsymbol{u}_{n}\right\rangle=0$

and $\boldsymbol{u}_{1}\|=1,\| \boldsymbol{u}_{2}\|=1,\| \boldsymbol{u}_{3} \|=1$,

$\ldots,\left\|\boldsymbol{u}_{n}\right\|=1$

- From Definition 4.2.1 we have that orthonormal based is ortogonal, but we cannot always justify if a statement is reversed

\section{Theorem 4.2.2}

Let $\boldsymbol{u}_{1}, \boldsymbol{u}_{2}, \ldots, \boldsymbol{u}_{n}$ be an orthonormal bases in a vector space $V$ with inner product $\langle$,$\rangle . Then for$ every $v \in V$,

$$
\boldsymbol{v}=a_{1} \boldsymbol{u}_{1}+a_{2} \boldsymbol{u}_{2}+\cdots+a_{n} \boldsymbol{u}_{n}
$$

which $a_{i}=\left\langle\boldsymbol{v}, \boldsymbol{u}_{i}\right\rangle, i=1,2, \ldots, n$.

Proof.

Since $\left\{\boldsymbol{u}_{1}, \boldsymbol{u}_{2}, \cdots, \boldsymbol{u}\right\}$ is a bases in $V$, then for every

$\boldsymbol{v} \in, \boldsymbol{v}=a_{1} \boldsymbol{u}_{1}+a_{2} \boldsymbol{u}_{2}+\cdots+a_{n} \boldsymbol{u}_{n}$

It's shown that $a_{i}=<\boldsymbol{v}, \boldsymbol{u}_{i}>$. Consider that

$$
\begin{aligned}
<\boldsymbol{v}, \boldsymbol{u}_{i}>= & <a_{1} \boldsymbol{u}_{1}+a_{2} \boldsymbol{u}_{2}+\cdots \\
& +a_{n} \boldsymbol{u}_{n}, \boldsymbol{u}_{i}> \\
& =<a_{1} \boldsymbol{u}_{1}, \boldsymbol{u}_{i}>+< \\
a_{2} \boldsymbol{u}_{2}, \boldsymbol{u}_{i}>+\cdots+ & <a_{n} \boldsymbol{u}_{n}, \boldsymbol{u}_{i}> \\
& =a_{1}<\boldsymbol{u}_{1}, \boldsymbol{u}_{i}>+a_{2} \\
& <\boldsymbol{u}_{2}, \boldsymbol{u}_{i}>+\cdots+a_{n} \\
& <\boldsymbol{u}_{n}, \boldsymbol{u}_{i}> \\
& =a_{1} 0+a_{2} 0+\cdots+ \\
a_{i} 1+\cdots+a_{n} 0 & \\
& =a_{i}
\end{aligned}
$$

Remark:

- Theorem 4.2.2 states that if $\left\{\boldsymbol{u}_{1}, \boldsymbol{u}_{2}, \ldots\right.$, $\left.\boldsymbol{u}_{n}\right\}$ is an orthonormal bases in vector space $V$ with inner product, then $a_{i}$ in $\boldsymbol{v}=a_{1} \boldsymbol{u}_{1}+a_{2} \boldsymbol{u}_{2}+\cdots+a_{n} \boldsymbol{u}_{n}$ can be calculated in a way: $a_{i}=$ $\left\langle\boldsymbol{v}, \boldsymbol{u}_{i}\right\rangle, i=1,2, \ldots, n$, atau $a_{1}=$ $\left\langle\boldsymbol{v}, \boldsymbol{u}_{1}\right\rangle, a_{2}=\left\langle\boldsymbol{v}, \boldsymbol{u}_{2}\right\rangle, a_{3}=$ $\left\langle\boldsymbol{v}, \boldsymbol{u}_{3}\right\rangle, \ldots, a_{n}=\left\langle\boldsymbol{v}, \boldsymbol{u}_{n}\right\rangle$.

Review that $\tilde{a_{i}}$ in a arbitrary vector space, can be calculated using this way, that is: Let $\left\{\left(\begin{array}{l}1 \\ 2 \\ 1\end{array}\right),\left(\begin{array}{l}1 \\ 0 \\ 1\end{array}\right),\left(\begin{array}{l}1 \\ 0 \\ 0\end{array}\right)\right\}$ bases in $\mathbb{R}^{3}$, then vector $\left(\begin{array}{l}1 \\ 2 \\ 3\end{array}\right) \in \mathbb{R}^{3}$ is linearly combination from bases vector, i.e $\left(\begin{array}{l}1 \\ 2 \\ 3\end{array}\right)=a_{1}\left(\begin{array}{l}1 \\ 2 \\ 1\end{array}\right)+a_{2}\left(\begin{array}{l}1 \\ 0 \\ 1\end{array}\right)+$ $a_{3}\left(\begin{array}{l}1 \\ 0 \\ 0\end{array}\right)$. Calculate $a_{1}, a_{2}, a_{3}$ by If bases in vector space is orthogonal, as above, for example $\left\{\left(\begin{array}{l}0 \\ 1 \\ 0\end{array}\right),\left(\begin{array}{l}1 \\ 0 \\ 1\end{array}\right),\left(\begin{array}{c}1 \\ 0 \\ -1\end{array}\right)\right\}$ is orthogonal bases in $\mathbb{R}^{3}$ with dot product is inner product in $\mathbb{R}^{3}$, then vector $\left(\begin{array}{l}1 \\ 2 \\ 3\end{array}\right) \in \mathbb{R}^{3}$ can be write $\left(\begin{array}{l}1 \\ 2 \\ 3\end{array}\right)=$ $a_{1}\left(\begin{array}{l}0 \\ 1 \\ 0\end{array}\right)+a_{2}\left(\begin{array}{l}1 \\ 0 \\ 1\end{array}\right)+a_{3}\left(\begin{array}{c}1 \\ 0 \\ -1\end{array}\right)$.

To calculated $a_{1}, a_{2}, a_{3}$ with two way, that is using elementary row

$$
\begin{aligned}
& \left\langle\left(\begin{array}{l}
1 \\
2 \\
3
\end{array}\right),\left(\begin{array}{l}
0 \\
1 \\
0
\end{array}\right)\right\rangle, a_{2}= \\
& \left\langle\left(\begin{array}{l}
1 \\
2 \\
3
\end{array}\right),\left(\begin{array}{l}
1 \\
0 \\
1
\end{array}\right)\right\rangle, a_{3}=\left\langle\left(\begin{array}{l}
1 \\
2 \\
3
\end{array}\right),\left(\begin{array}{c}
1 \\
0 \\
-1
\end{array}\right)\right\rangle .
\end{aligned}
$$

(exercises for you!)

This design is called the author as the design of providing step-by-step information. This lecture material is given to students through whatsapp groups and continued with discussion. 


\subsection{Result and Discussion}

Based on observations to students (44 students), the following results are obtained:

Table 4. Percentages Understanding Student per Topic (Without Blended Learning)

\begin{tabular}{lcccccc}
\hline \multicolumn{1}{c}{ Grade } & Score & \multicolumn{5}{c}{ Topic $(\%)$} \\
\hline & & I & II & III & IV & V \\
Less & $0-5$ & 43 & 5 & 11 & 16 & 59 \\
Sufficient & $6-10$ & 27 & 25 & 16 & 20 & 5 \\
Good & $11-15$ & 7 & 68 & 61 & 16 & 7 \\
Very Good & $16-20$ & 23 & 2 & 11 & 48 & 30 \\
\hline
\end{tabular}

Table 5. Percentages Understanding Student per Topic (With Blended Learning)

\begin{tabular}{lccccc}
\hline \multicolumn{1}{c}{ Grade } & Score & \multicolumn{4}{c}{ Topic (\%) } \\
\hline & & I & II & III & IV \\
Less & $0-6$ & 2 & 41 & 45 & 93 \\
Sufficient & $7-13$ & 7 & 23 & 2 & 5 \\
Good & $14-19$ & 23 & 23 & 2 & 0 \\
Very Good & $20-25$ & 14 & 14 & 50 & 2 \\
\hline
\end{tabular}

Based on Tables 3 and 4, it was found that each topic has a different level of understanding by students. It can be seen that the use of blended learning does not have a significant effect on increasing students' understanding.

Next, given the students' final exam scores.

Table 6. Percentages Final Exam 2019/2020

\begin{tabular}{cccc}
\hline Grade & Score & Number of Student & Percentage \\
\hline A & $80 \leq x \leq 100$ & 5 & 11.36 \\
A- & $75 \leq x<80$ & 4 & 9.09 \\
B+ & $70 \leq x<75$ & 6 & 13.64 \\
B & $65 \leq x<70$ & 9 & 20.45 \\
B- & $60 \leq x<65$ & 7 & 15.91 \\
C+ & $55 \leq x<60$ & 4 & 9.09 \\
C & $50 \leq x<55$ & 3 & 6.82 \\
D & $40 \leq x<50$ & 3 & 6.82 \\
E & $0 \leq x<40$ & 3 & 6.82 \\
\hline
\end{tabular}

Compare with

Table 7. Percentages Final Exam 2018/2019

\begin{tabular}{cccc}
\hline Grade & Score & Number of Student & Percentage \\
\hline A & $80 \leq x \leq 100$ & 6 & 13.64 \\
A- & $75 \leq x<80$ & 4 & 11.36 \\
B+ & $70 \leq x<75$ & 3 & 4.55 \\
B & $65 \leq x<70$ & 4 & 9,09 \\
B- & $60 \leq x<65$ & 5 & 11.36 \\
C+ & $55 \leq x<60$ & 7 & 15.91 \\
\hline C & $50 \leq x<55$ & 7 & 15.91 \\
\hline D & $40 \leq x<50$ & 9 & 18.81 \\
\hline E & $0 \leq x<40$ & 0 & 0 \\
\hline
\end{tabular}




\section{CONCLUSION}

Although blended learning does not have a significant effect on elementary linear algebra but in general, blended learning method can increase student's understanding to Elementary Linear Algebra.

\section{ACKNOWLEDGMENTS}

This work supported by LP3M Grand Andalas University, No. T.37/UN.16.18/PT.01.03/2020

\section{REFERENCES}

[1] Garrison, D. R. \& Kanuka, H. Blended learning: uncovering its transformative potential in higher education. Internet and Higher Education, Vol. 7, No. 2, pp. 95-105 (2004)

[2] Ginns, P. \& Ellis, R. A. Evaluating the quality of e-learning at the degree level in the student experience of blenden learning. British Journal of Educational Tecnology, Vol. 40, No. 4, pp. 652-663 (2009)

[3] Graham, C. R. Blended learning system: definition, current trend, and future direction. Dalam C. J. Bonk \& C. R. Graham (eds), The handbook of blended learning; Global Perpectives, local designs. San Fransisco, CA; Pfeiffer, (2006)
[4] Lopez-Perez, M. V., Perez-Lopez, M. C. \& Rodrigues_Ariza, L. Blended Learning in higher education: Students' perception and their relation outcomes. Computer \& Education, Vol. 56, pp. 818-826 (2011).

[5] Macdonald, J. Blended learning and online tutoring (2nd ed.) Hampishire, UK: Gower. (2008)

[6] Mitchell, P. \& Forer, P. 2010. Blended learning: the perception of first-years geography student. Journal of Geography in Higher Education, Vol. 34, No. 1, pp. 77- 89.

[7] Paetchter, M. \& Maier, B. Online or face- to-face? Student experiences and preferences in elearning. Internet and Higher Education, Vol. 13, pp. 292-297 (2010).

[8] Thorne, K. Blended Learning: How to Integrate Online and Traditional Learning, Kohan Page Limited, USA. (2003) 